\title{
Metabolomic profile of amniotic fluid to evaluate lung maturity: the diaphragmatic hernia lamb model
}

\author{
Gloria Pelizzo ${ }^{1 *}$, Maurizio Ballico ${ }^{2}$, Maria Chiara Mimmi ${ }^{2}$, José Louis Peirò ${ }^{3}$, Mario Marotta ${ }^{4}$, Costanzo Federico $^{1}$, \\ Erika Andreatta ${ }^{1}$, Ghassan Nakib ${ }^{1}$, Maurilio Sampaolesi ${ }^{5}$, Elisa Zambaiti ${ }^{1}$ and Valeria Calcaterra ${ }^{1,6}$
}

\begin{abstract}
Background: Tracheal occlusion (TO) stimulates lung growth in fetuses affected with congenital diaphragmatic hernia $(C D H)$ although the processes involved in lung maturation still remain unknown. The objective of this study was to evaluate the metabolomic profile of amniotic fluid (AF) following TO in fetal lamb model in order to obtain an indirect view of mechanisms involved in pulmonary reversal hypoplasia and biochemical maturity in response to fetal TO.

Methods: Liquid Chromatography Mass Spectrometry was performed on lamb AF samples at: age I (70 days' gestation); age II (102 days' gestation); age III (136 days' gestation). CDH was induced at age I and TO at age II.

Results: Betaine, choline, creatinine were found significantly increased during gestation in the control group. The CDH group showed choline ( $p=0.007)$ and creatinine $(p=0.004)$ decreases during pregnancy. In the TO group choline and creatinine profiles were restored.

Conclusions: Alveolar tissue and fetal global growth ameliorated after TO. Metabolomics provided useful information on biochemical details during lung maturation. Metabolomic profiling would help to identify the best time to perform TO, in order to increase survival of $\mathrm{CDH}$ affected patients.
\end{abstract}

Keywords: Amniotic fluid, Animal model, Congenital diaphragmatic hernia, Metabolomic, Tracheal occlusion

\section{Background}

Congenital diaphragmatic hernia $(\mathrm{CDH})$ is a congenital birth defect that occurs in $1 / 2000$ to $1 / 3000$ newborns with a survival rate of $42-68 \%$. Abnormal development of the pulmonary parenchyma and vasculature lead to variable degrees of respiratory insufficiency and pulmonary hypertension in early neonatal life [1-4].

While modern neonatal intensive care has improved the prognosis for surviving cases, comorbidities affect almost half of live-born infants and the mortality rate remains high in patients with poor prenatal prognosis. Experimental studies could potentially ameliorate outcomes in pulmonary hypoplasia [5,6]. Fetal endoscopic

\footnotetext{
* Correspondence: g.pelizzo@smatteo.pv.it

'Department of the Mother and Child Health, Pediatric Surgery Unit, Fondazione IRCCS Policlinico San Matteo, Pavia and University of Pavia, Piazzale Golgi 2, 27100 Pavia, Italy

Full list of author information is available at the end of the article
}

tracheal occlusion (FETO) may still be a possible therapeutic procedure in case of severe $\mathrm{CDH}$, even if the mortality rate is reported to be nearly $40 \%$ [7-9].

Amniotic fluid (AF) composition reflects the physiological status during fetal development and it may be used to detect potential pathological conditions. AF contains large amounts of proteins and metabolites produced by the amnion epithelial cells, fetal tissues, fetal excretions and placental tissues.

Metabolomics is commonly used to measure the entire metabolomic profile in biological fluids, cells, tissues or organs and to elucidate the association between metabolic pathways and perturbations that arise as a result of disease or organ malformation [10-13].

The objective of this study was to determine amniotic fluid metabolic profiling changes in fetal lambs who underwent surgically induced $\mathrm{CDH}$ and subsequent tracheal occlusion (TO) which provides an excellent vision 
of lung biochemical maturity and is an excellent model to determine the real benefits and best timing for TO.

\section{Methods}

The experimental protocol was approved by the National Animal Care and Ethics Committee and was conducted in accordance with Italian and European legislation (D.lgs. 116/92, European Directives 86/609/EE for the protection of animals used in scientific and experimental studies and 2010-63UE).

A preliminary study with Liquid Chromatography Mass Spectrometry (LC-MS) [14,15] was performed on 20 lamb AF samples, taken at three gestational ages: Age I (70 days' of gestation); Age II (102 days' gestation); Age III (136 days' gestation).

$\mathrm{CDH}$ induction was performed at Age I and TO was carried out during the $2^{\text {nd }}$ trimester at Age II.

Based on this information, AF samples were divided into:

- - CONTROL group, healthy control pregnancies: Age I, number of samples $=5$; Age II, number of samples =3; Age III, number of samples =3;

- - CDH group, fetuses with induced CDH: Age II, number of samples $=3$ and at Age III, number of samples $=3$;

- $-\mathrm{CDH}+\mathrm{TO}$ group, fetuses with induced $\mathrm{CDH}$ and TO treatment: Age III, number of samples $=3$

Healthy control AF samples were collected to study the normal metabolomic evolution.

We report on the effect of induced $\mathrm{CDH}$ and $\mathrm{TO}$ treatment for selected metabolites at stage Age III.

\section{Anesthesia protocol}

All surgical procedures were performed under general anesthesia. After premedication with intramuscular (IM) injection of $5 \mathrm{mg} / \mathrm{Kg}$ ketamine and $0.2 \mathrm{mg} / \mathrm{Kg}$ midazolam (Dormicum ${ }^{\oplus}$, Roche), intravenous access (IV) was established at the external jugular vein.

The pregnant ewes were pre-oxygenated using a facemask and induced with $5 \mathrm{mg} / \mathrm{Kg}$ IV propophol (Propofol ${ }^{\circledR}$-Lipuro 1\%, B. Braun Melsungen AG). Endotracheal intubation was performed, and general anesthesia was maintained with isoflurane $2 \%$ (Isoflo, Abbott laboratories Ltd) in $100 \%$ oxygen ( $1.5 \mathrm{~L} /$ minute).

Esophageal intubation was performed to prevent ruminal bloat. A continuous infusion of Ringer lactate (B. Braun Melsungen AG) was administered at $10 \mathrm{ml} / \mathrm{Kg} / \mathrm{h}$ during surgery. Intra-operative monitoring consisted of electrocardiography, pulse oximetry, non invasive blood pressure and capnography. All animals received a $75 \mu \mathrm{g}$ transdermal fentanyl patch (Durogesic ${ }^{\oplus}$, Janssen laboratories) for post-operative pain relief. For peri-operative infection prophylaxis, the animals received a single dose of $22 \mathrm{mg} / \mathrm{Kg}$ IV cephazolin (Kurgan ${ }^{\circ}$, Normon Laboratories) at the time of induction and $15 \mathrm{mg} / \mathrm{Kg}$ IM amoxicillin (Duphamox L. A., Fort Dodge) every 48 h, for eight days. Fetuses were anesthetized through the placenta and additional anesthesia with fentanil $(10 \mu \mathrm{g} / \mathrm{kg} \mathrm{IM})$ and the muscle relaxant pancuronium $(0.3 \mathrm{mg} / \mathrm{Kg} \mathrm{IM})$ were administered. Meloxicam $0.5 \mathrm{mg} / \mathrm{kg} \mathrm{IM} / 24 \mathrm{~h}$ was administered as post-operative analgesia for seven days. Maternal body temperature was monitored by using a digital probe and maintained at 36$37^{\circ} \mathrm{C}$ with a warming bed. Standard ECG electrodes were used for monitoring.

\section{Surgical technique}

As a first step, malformation was surgically induced (day 70 of gestation). A midline laparotomy exposed the gravid uterus. The fetus was partially extruded from the uterus with a short hysterectomy $(4 \mathrm{~cm})$. A left fetal thoracotomy was achieved and a diaphragmatic hernia was created. The fetal stomach was raised into the thorax, which was closed into one layer. The fetus was returned to the uterus ( $2 \mathrm{gr}$ of amoxicillin were added to the amniotic fluid). The uterus wall and maternal laparotomy were closed.

The next step included the tracheal occlusion (day 102 of gestation). The uterus was externalized after a midline laparotomy. The fetal lamb's mouth was located and also partially externalized by a short hysterectomy $(2 \mathrm{~cm})$. A latex detachable balloon was placed into the trachea and inflated. The fetus was returned to the uterus and $2 \mathrm{gr}$ of amoxicillin were added to the amniotic fluid. Closure of the uterus and the abdomen walls was performed.

At the end of the pregnancy (day 136 of gestation), lambs were delivered via terminal caesarean section, approximately 10 days before term to prevent natural parturition. Lambs were euthanized with a bolus of Pentobarbital $200 \mathrm{mg} / \mathrm{Kg} \mathrm{IV}$.

\section{Metabolomic analysis Sample preparation}

Amniotic fluid samples were centrifuged after collection in order to remove cells and cellular debris. The supernatants were immediately frozen and stored at $-70^{\circ} \mathrm{C} /-80^{\circ} \mathrm{C}$ until metabolite extraction and analysis were performed. Supernatant samples were thawed at room temperature and methanol extraction was accomplished with the protocol reported by Graca et al. [16]. An internal standard (2'-deoxyadenosine) was added to the extracted dry aliquots which were reconstituted in ultrapure $\mathrm{H}_{2} \mathrm{O}$ (Milli-Q $\mathrm{H}_{2} \mathrm{O}$ ).

\section{HPLC-TOF-MS analysis}

LC-MS analysis was performed by positive ionization mass spectrometry using a Q-STAR mass spectrometer (AB-SCIEX, Foster City, CA, USA) equipped with an 
electrospray ionization source; acquired data were analyzed using AB-SCIEX Analyst ${ }^{\mathrm{TM}}$ QS software (version 1.1). The HPLC system includes an Agilent 1100 series micro LC pump. The liquid chromatographic separation was performed on a Jupiter $5 \mu \mathrm{m} 300 \AA(150 \times 0.5 \mathrm{~mm})$ Reverse PhaseC18 column (PhenomenexInc, Torrance, CA, USA) at a flow of $10 \mu \mathrm{L} / \mathrm{min}$ using a gradient from $0 \%$ to $90 \%$ of solvent Bover $35 \mathrm{~min}$. Solvents A and Bconsisted of water and acetonitrile, respectively; both contained $0.1 \%(\mathrm{v} / \mathrm{v})$ formic acid. All samples were analyzed in triplicate.

Metabolites were quantified using LC-MS-TOF standard runs in positive-ion mode, while LC-MS/MS runs were used for molecule identification. The assignment of the metabolites was based on analytical standards analyzed under the same chromatographic conditions.

\section{Data processing and analysis}

The metabolite peaks from raw HPLC-MS chromatograms were integrated with the software Analyst QS 1.1 (Applied Biosystems-SCIEX) by evaluating the extracted ion chromatogram (XIC) counts. All data sets were normalized to account for variable sample dilution and experimental influences using the peak area of the internal standard (2'-deoxyadenosine).

The HPLC-MS data shown in Tables 1, 2 and 3 represent the metabolite XIC areas, which do not account for concentrations, but can be used to evaluate the relative level of each metabolite among the three sample groups (Control Age I/II/III, CDH Age II/III and CDH + TO Age III).

A comparison of Age II groups (Control II and $\mathrm{CDH}$ II) and among Age III groups (Control III, CDH III and $\mathrm{CDH}+\mathrm{TO}$ III) was performed and the One-Way Analysis of Variance (ANOVA) was applied to determine

Table 1 Metabolite MS peak area (Intensity Counts) in ovine amniotic fluid from a fetal lamb model of congenital diaphragmatic hernia (CDH) and tracheal occlusion (TO)

\begin{tabular}{|c|c|c|c|c|c|c|}
\hline \multicolumn{7}{|c|}{ MS peak area } \\
\hline \multirow[b]{2}{*}{ Metabolite } & \multirow{2}{*}{$\begin{array}{l}\text { Age I } \\
\text { (70 days) } \\
\text { Control }\end{array}$} & \multicolumn{2}{|c|}{$\begin{array}{l}\text { Age II } \\
\text { (102 days) }\end{array}$} & \multicolumn{3}{|c|}{$\begin{array}{l}\text { Age III } \\
\text { (136 days) }\end{array}$} \\
\hline & & Control & $\mathrm{CDH}$ & Control & $\mathrm{CDH}$ & $\mathrm{CDH}+\mathrm{TO}$ \\
\hline \multirow[t]{3}{*}{ Betaine } & 7931 & 19140 & 17905 & 91450 & 17210 & 27990 \\
\hline & \pm & \pm & \pm & \pm & \pm & \pm \\
\hline & 426 & 750 & 944 & 2646 & 566 & 901 \\
\hline \multirow[t]{3}{*}{ Choline } & 1500 & 4793 & 3667 & 6281 & 1639 & 3933 \\
\hline & \pm & \pm & \pm & \pm & \pm & \pm \\
\hline & 179 & 381 & 118 & 375 & 146 & 14 \\
\hline \multirow[t]{3}{*}{ Creatinine } & 687 & 19988 & 17115 & 189533 & 20330 & 118833 \\
\hline & \pm & \pm & \pm & \pm & \pm & \pm \\
\hline & 77 & 968 & 609 & 7821 & 495 & 3612 \\
\hline
\end{tabular}

Data are expressed as group means \pm standard deviation.
Table 2 Metabolite MS peak area (Intensity Counts) in Age II ovine amniotic fluid

\begin{tabular}{lllll}
\hline Age II AF & \multicolumn{2}{l}{ MS peak area } & Fold Difference & $\mathbf{p}$ \\
\cline { 2 - 3 } Metabolite & Control & $\mathbf{C D H}$ & & 0.089 \\
\hline Betaine & 19140 & 17905 & 1.07 & \\
& \pm & \pm & & 0.007 \\
Choline & 750 & 944 & & \\
& 4793 & 3667 & 1.31 & \\
& \pm & \pm & & 0.004 \\
Creatinine & 381 & 118 & & \\
& 19988 & 17115 & 1.17 & \\
& \pm & \pm & & \\
& 968 & 609 & & \\
\hline
\end{tabular}

Data are expressed as group means \pm standard deviations. $p$ refers to Welch's ANOVA.

whether the means of groups significantly differed. We performed Welch's ANOVA, which does not assume constant variance across all groups, with an alpha level set at 0.05 . In the case of Age III, sample differences between all pairs of groups were compared according to the Games-Howell method, which does not assume constant variance while controlling the multiple comparisons error rate.

\section{Results}

The AF analysis in control samples (gestational Ages I to III) led to the identification of potentially interesting molecules in the amniotic fluid, including amino acids, organic acids, sugars and nucleotide metabolites. Among these, we observed that only three metabolites,betaine, choline and creatinine, continuously increased during ovine gestation, while all the other identified metabolites exhibited a variable trend including increasing and decreasing phases. This made the mentioned metabolites the best biomarkers of a physiological pregnancy and we therefore focused on these three compounds and analysed their variation following induced $\mathrm{CDH}$ and $\mathrm{TO}$ treatment.

According to the ANOVA analysis of age II groups (102 days), $\mathrm{CDH}$ induces a significant decrease in choline ( $p$ 0.007) and creatinine ( $p 0.004)$, while betaine alterations were not significant (p 0.089) (Figure 1 and Table 1).

The most significant alterations observed were in AF collected at Age III (136 days), since at this stage the effect of $\mathrm{CDH}$ could be evaluated either with or without the TO treatment.

The results from non-treated $\mathrm{CDH}$, in comparison with healthy controls, resulted in the following adjusted $\mathrm{p}$ values: choline ( $p 0.001)$, creatinine ( $p$ 0.001) and betaine ( $p 0.000)$ (Figure 1 and Table 2).

Interestingly, the TO treatment led to a substantial recovery in choline and creatinine levels and to a modest 
Table 3 Metabolite MS peak area (Intensity Counts) in Age III ovine amniotic fluid

\begin{tabular}{|c|c|c|c|c|c|c|c|c|c|c|c|c|c|c|c|}
\hline \multirow{2}{*}{$\begin{array}{l}\text { Age III AF } \\
\text { Metabolites }\end{array}$} & \multicolumn{2}{|c|}{ MS peak area } & \multirow[t]{2}{*}{ Fold difference } & \multirow[t]{2}{*}{ Adjusted $\mathrm{p}$} & \multirow[t]{2}{*}{$\mathbf{t}$} & \multicolumn{2}{|c|}{ MS peak area } & \multirow[t]{2}{*}{ Fold difference } & \multirow[t]{2}{*}{ Adjusted $p$} & \multirow[t]{2}{*}{$\mathbf{t}$} & \multicolumn{2}{|c|}{ MS peak area } & \multirow[t]{2}{*}{ Fold difference } & \multirow[t]{2}{*}{ Adjusted $\mathrm{p}$} & \multirow[t]{2}{*}{$\mathbf{t}$} \\
\hline & Control & $\mathrm{CDH}$ & & & & Control & $\mathrm{CDH}+\mathrm{TO}$ & & & & $\mathrm{CDH}+\mathrm{TO}$ & $\mathrm{CDH}$ & & & \\
\hline \multirow[t]{3}{*}{ Betaine } & 91450 & 17210 & 5.31 & 0.000 & 47.02 & 91450 & 27990 & 3.27 & 0.000 & 39.33 & 27990 & 17210 & 1.63 & 0.001 & 16.43 \\
\hline & \pm & \pm & & & & \pm & \pm & & & & \pm & \pm & & & \\
\hline & 2646 & 566 & & & & 2646 & 901 & & & & 901 & 566 & & & \\
\hline \multirow[t]{3}{*}{ Choline } & 6281 & 1639 & 3.83 & 0.001 & 19.36 & 6281 & 3933 & 1.60 & 0.015 & 10.84 & 3933 & 1639 & 2.40 & 0.042 & 22.10 \\
\hline & \pm & \pm & & & & \pm & \pm & & & & \pm & \pm & & & \\
\hline & 375 & 146 & & & & 375 & 14 & & & & 14 & 146 & & & \\
\hline \multirow[t]{3}{*}{ Creatinine } & 189533 & 20330 & 9.32 & 0.001 & 37.36 & 189533 & 118833 & 1.60 & 0.002 & 14.21 & 118833 & 20330 & 5.84 & 0.001 & 46.59 \\
\hline & \pm & \pm & & & & \pm & \pm & & & & \pm & \pm & & & \\
\hline & 7821 & 495 & & & & 7821 & 3612 & & & & 3612 & 495 & & & \\
\hline
\end{tabular}

Data are expressed as group means \pm standard deviation. Adjusted $\mathrm{p}$ and $\mathrm{t}$ were obtained with the One-way ANOVA with Games-Howell Pairwise Comparisons. 


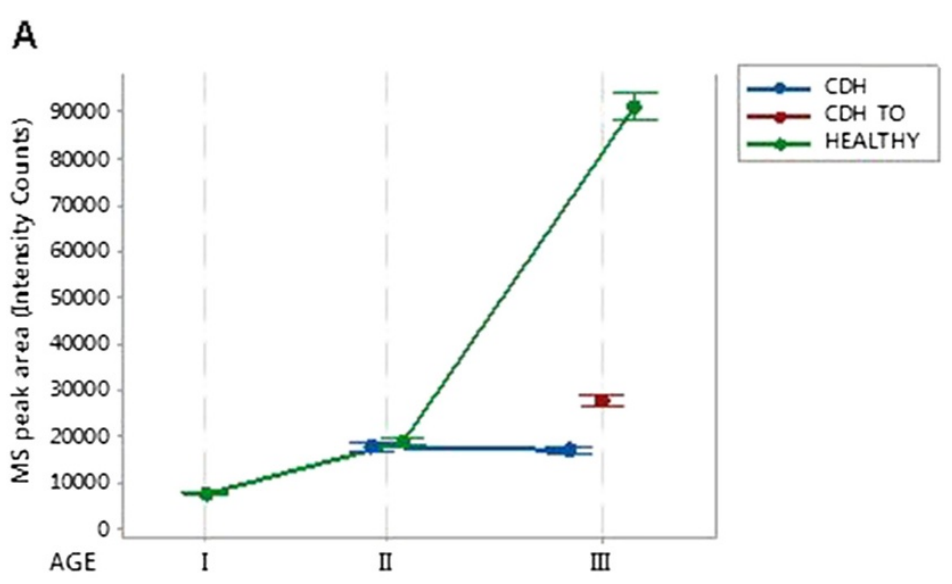

B

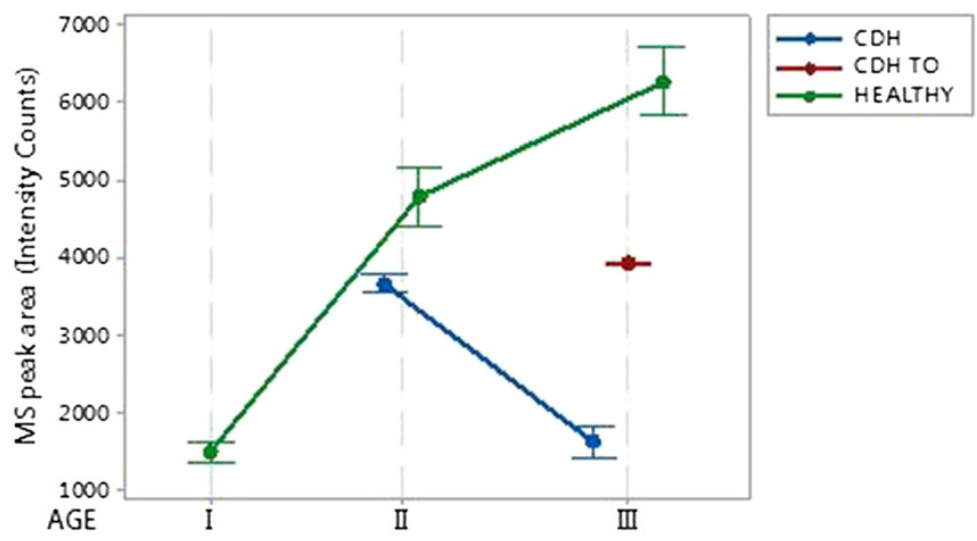

C

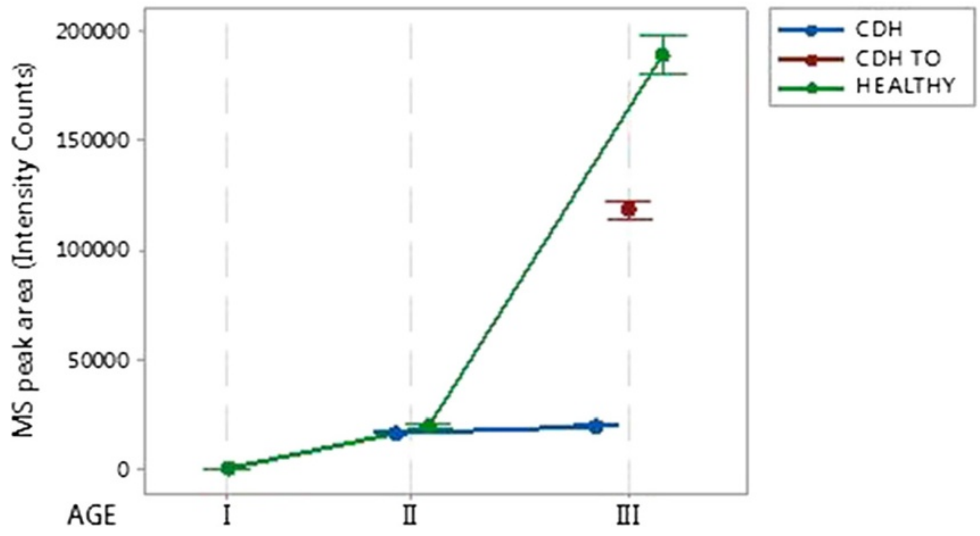

Figure 1 Metabolomic data summarized in Table 1. The Interval Plots show the trend exhibited by the three metabolic markers: betaine (panel A), choline (panel B) and creatinine (panel C) during gestation in the case of "control/CDH induced/CDH induced and TO" treatedfetal lambs. Bullets represent the group mean values, while the interval bars extend 2 standard errors away from the mean.

recovery in betaine (Figure 1). The ANOVA analysis of the Age III groups and the following Games Howell multiple comparison test are consistent with this trend (Figure 1 and Table 3). In particular, p obtained when comparing the control and $\mathrm{CDH}+\mathrm{TO}$ groups indicate that by the end of gestation, betaine, choline and creatinine were positively affected by the TO treatment and resulted closer to the physiological level. In fact, although the $\mathrm{p}$ indicate a significant difference between the control and $\mathrm{CDH}+\mathrm{TO}$ conditions, the comparison of fold difference values between control and CDH samples, with and without TO, show a significant recovery 
of the biomarkers associated with the TO treatment (Table 3).

\section{Discussion}

Amniotic fluid volume and composition are the result of the dynamic interaction between the secretion of fetal lung liquid, fetal urine and the removal of fluid by fetal swallowing and/or resorption through the fetal membranes [17]. A great amount of AF comes from epithelial lung. Between $47-54 \%$ of the lung secreted fluids comes out of fetal trachea and are swallowed and the rest is mixed with the amniotic fluid during breathing movements [17].

Metabolomics of human AF has been recently used to detect different fetal pathologies in pregnancy such as chromosomal disorders [18-20], renal dysfunction [10,21], metabolic disease [10], neural tube anomalies [10,22-24] and defects of intrauterine growth [25-28]. Recent advances in metabolomics [10-13,29] also introduce AF evaluation as a new approach to fetal pulmonary development studies.

Preliminary data of our study show an interesting increase in choline, betaine and creatinine levels during physiologic pregnancy. The profile of these metabolites increases constantly during gestational age. These molecules are detectable in AF in different concentrations, according to the gestational period $[11,12]$. Changes in the gestational choline profile have already been correlated with the fetal lung maturity [30]. Choline seems to be involved in the synthesis of phospholipid, a major surfactant component. The role of betaine is unclear; it is formed by choline oxidation catalyzed by the mitochondrial enzyme choline dehydrogenase $[16,30,31]$. Betaine is also engaged in pulmonary development in the same metabolic pathway as choline. Creatinine has also been used long as a test of fetal maturity. Bock showed that in relation to maturity of the fetus, the relative intensity of the creatinine peak correlated best with conventional tests of fetal lung maturity [12]. Choline and creatinine are involved in development of different fetal organs. The possibility that the profile of these metabolites may be influenced by other variables, such as the fetal renal system, cell membrane turnover, cannot be excluded.

Newborns with $\mathrm{CDH}$ have hypoplastic lung. These patients have normal maturation values for alveolar epithelial type II. At birth, surfactant and phospholipid production is not delayed [31,32]; the total amount of cells is reduced, as expected in a hypoplasia condition. Prenatal TO to treat severe $\mathrm{CDH}$ seems to improve pulmonary growth $[1-4,33,34]$. TO prevents egress of pulmonary fluid leading to lung tissue stretching and reversal of lung hypoplasia. The lung parenchymal structure increases in alveolar growth and interalveolar wall thickness. In the animal model, sustained FETO causes type II cell depletion resulting in significantly low surfactant production. Temporary FETO fails to cause lung growth in the $\mathrm{CDH}$ model, but it preserves type II cells, surfactant production, and partially corrects abnormal muscularization of pulmonary arterioles seen in pulmonary hypertension [31-36].

Our study confirms the perturbation of lung maturity in $\mathrm{CDH}$. Certain AF metabolites stop increasing from stage II to stage III in $\mathrm{CDH}$ fetuses. The intensity peaks of creatinine and betaine at stage III, at the end of gestation, were similar to those found at stage II but reduced in average compared to controls at the same gestational age (stage II). Choline intensity peaks in $\mathrm{CDH}$ fetuses were even found to be significantly lower during gestation than control specimens; growth curve did not increase from the beginning of gestation and values found at term were lower than those found in controls at stage I.

In this study, sustained TO was performed to reproduce the same conditions induced by FETO in CDH human fetuses. Surprisingly, fetal TO seems to improve the profile of the three metabolites: immediately at Age II after TO induction and at stage III gestation. Creatinine had the most improved metabolomic recovery profile, supporting the role of this metabolite as a marker of lung involvement in fetal development [12,30].

The mild response of betaine, with respect to creatinine and choline, could be related to the involvement of this metabolite in simultaneous methylation reactions which also include the development of fetal respiratory system.

Nuclear magnetic resonance (NMR) spectroscopy or mass spectrometry (MS) are employed to characterize metabolomic profiles and quantify all small molecules in biological samples. Thus a comprehensive global monitoring of metabolites and their fluctuations in response to various stimuli can be achieved. Metabolomic profiling can provide information on what is actually changing in a biological system, and serves as a crucial link between phenotype and genetics [13-16]. Simultaneous analysis of different groups of metabolic markers like amino acids (ie alanine), sugars (ie glucose) and muscle catabolites (ie creatinine) in a single MR spectrum allows indirect assessment of function and development of fetal organs [11-13]. The observed variation could also reflect the AFS cell composition in the AF. In this view, congenital diaphragmatic hernia could trigger AFS cell maturation according to tissue regeneration needs, resulting in a AF metabolic signature in the $\mathrm{CHD}$ lamb model [9].

There are no previous studies on the metabolomic profile of the amniotic fluid in the CDH lamb model after TO.

This approach provided an indirect index of fetal lung maturity, but the involvement of surfactant production of type II cells needs to be verified in further studies. Concomitant metabolomics, histological and immunochemical studies, are needed to confirm a direct correlation between AF profile, type II pneumocyte integrity and lung maturation before and after TO. 
Although this is a preliminary study, our findings support the hypothesis that the best biomarkers of a physiological pregnancy may be considered as suggestive indexes of lung maturity also in $\mathrm{CDH}$ fetuses. Increased knowledge of pulmonary maturation may be useful in defining biochemical mechanisms which are at the basis of lung hypoplasia in $\mathrm{CDH}$ fetuses. The effects of TO confirm their role in restoring the processes involved in surfactant-mediated lung maturation. This study also supports novelinvestigations in potential pathways implicated in AF regulatory mechanisms. Intra-tracheal pulmonary absorption could be considered an influent pathway in the amniotic fluid dynamics.

\section{Conclusions}

AF metabolomic profiles may be considered indirect markers of lung growth and could be useful in defining the prognosis of $\mathrm{CDH}$ fetuses. Metabolomic analysis in $\mathrm{AF}$ in a $\mathrm{CDH}$ animal model, provides useful information on fetal lung biochemical mechanisms involved in pulmonary development processes.

Further investigations are still needed to identify new biochemical macromolecules involved in fetal lung maturation to improve survival of severe $\mathrm{CDH}$ fetuses.

\section{Abbreviations \\ AF: Amniotic fluid; AFS: Amniotic fluid-derived stem; CDH: Congenital diaphragmatic hernia; FETO: Fetal endoscopic tracheal occlusion; NMR: Nuclear magnetic resonance; MS: mass spectrometry; TO: Tracheal occlusion; VEGF: Vascular endothelial growth factor.}

\section{Competing interests}

The authors declare that they have no competing interests.

\section{Authors' contributions}

GP, surgical support, writing of the final manuscript. MB, MCM,metabolomic analysis. JLP, MM, surgical support, preparation of the manuscript draft, GN, surgical support, preparation of the manuscript draft, MS, preparation of the manuscript draft. FC, EA, EZ, surgical support. VC, preparation of the manuscript draft, revision of the literature. All authors read and approved the final manuscript.

\section{Author details}

${ }^{1}$ Department of the Mother and Child Health, Pediatric Surgery Unit, Fondazione IRCCS Policlinico San Matteo, Pavia and University of Pavia, Piazzale Golgi 2, 27100 Pavia, Italy. Department of Medical and Biological Sciences, University of Udine, Udine, Italy. ${ }^{3}$ Cincinnati Fetal Center. Pediatric Surgery Division, CCHMC, Cincinnati, OH, USA. ${ }^{4}$ Fetal Surgery Program, Congenital Malformations Research Group, Research Institute of Hospital Universitari Vall d'Hebron, Edifici Infantil, Barcelona, Spain. ${ }^{5}$ Laboratory of Translational Cardiomyology, Stem Cell Interdepartmental Institute, KU Leuven and Human Anatomy, University of Pavia, Pavia, Italy. ${ }^{6}$ Department of Internal Medicine, University of Pavia, Pavia, Italy.

Received: 8 August 2014 Accepted: 23 September 2014

Published: 4 November 2014

\section{References}

1. Badillo A, Gingalewski C: Congenital diaphragmatic hernia: treatment and outcomes. Semin Perinatol 2014, 38:92-96.

2. Haroon J, Chamberlain RS: An evidence-based review of the current treatment of congenital diaphragmatic hernia. Clin Pediatr (Phila) 2013, 52:115-124.

3. Leeuwen L, Fitzgerald DA: Congenital diaphragmatic hernia. J Paediatr Child Health 2014, 50:667-673.
4. Deprest JAM, Veerle A, Evrard K, Verbeken EK, Perales AJ, Delaere PR, Lerut TE, Flageole $\mathrm{H}$ : Tracheal side effects of endoscopic balloon tracheal occlusion in the fetal lamb model. Eur J Obstet Gynecol Reprod Biol 2000, 92:119-126.

5. Chiu PP: New Insights into Congenital Diaphragmatic Hernia - A Surgeon's introduction to CDH animal models. Front Pediatr 2014, 2:36.

6. Gallot D, Coste K, Jani J, Roubliova X, Marceau G, Velemir L, Verheyen A, Lemery D, Sapin V, Deprest J: Effects of maternal retinoic acid administration in a congenital diaphragmatic hernia rabbit model. Pediatr Pulmonol 2008, 43:594-603.

7. Ruano R, Yoshisaki CT, da Silva MM, Ceccon ME, Grasi MS, Tannuri U, Zugaib M, Ceccon ME, Grasi MS, Tannuri U, Zugaib M: A randomized controlled trial of fetal endoscopic tracheal occlusion versus postnatal management of severe isolated congenital diaphragmatic hernia. Ultrasound Obstet Gynecol 2012, 39:20-27.

8. Jani JC, Nicolaides KH, Gratacós E, Valencia CM, Doné E, Martinez JM, Gucciardo L, Cruz R, Deprest JA: Severe diaphragmatic hernia treated by fetal endoscopic tracheal occlusion. Ultrasound Obstet Gynecol 2009, 34:304-310.

9. Deprest J, Gucciardo L, Eastwood P, Zia S, Jimenez J, Russo F, Lesage F, Lewi L, Sampaolesi M, Toelen J: Medical and regenerative solutions for congenital diaphragmatic hernia: a perinatal perspective. Eur $J$ PediatrSurg 2014, 24:270-277.

10. Fanos V, Atzori L, Makarenko K, Melis GB, Ferrazzi E: Metabolomics application in maternal-fetal medicine. Biomed Res Int 2013, 2013:720514.

11. Cohn BR, Fukuchi EY, Joe BN, Swanson MG, Kurhanewicz J, Yu J, Caughey $A B$ : Calculation of gestational age in late second and third trimesters by ex vivo magnetic resonance spectroscopy of amniotic fluid. Am J Obstet Gynecol 2010, 203:76.e1-76.e10.

12. Cohn BR, Joe BN, Zhao S, Kornak J, Zhang WY, Iman R, Kurhanewicz J, Vahidi K, Yu J, Caughey AB, Swanson MG: Quantitative metabolic profiles of 2nd and 3rd trimester human amniotic fluid using (1) H HR-MAS spectroscopy. MAGMA 2009, 22:343-352.

13. Joe BN, Vahidi $\mathrm{K}$, Zektzer A, Chen MH, Clifton MS, Butler T, Keshari $\mathrm{K}$, Kurhanewicz J, Coakley F: Swanson MG: (1) H HR-MAS spectroscopy for quantitative measurement of choline concentration in amniotic fluid as a marker of fetal lung maturity: inter- and intraobserver reproducibility study. J Magn Reson Imaging 2008, 28:1540-1545.

14. Dunn WB, Broadhurst D, Begley P, Zelena E, Francis-Mclntyre S, Anderson N, Brown M, Knowles JD, Halsall A, Haselden JN, Nicholls AW, Wilson ID, Kell DB, Goodacre R: Human Serum Metabolome (HUSERMET) Consortium: Procedures for large-scale metabolic profiling of serum and plasma using gas chromatography and liquid chromatography coupled to mass spectrometry. Nat Protoc 2011, 6:1060-1083.

15. Zhu Z, Schultz AW, Wang J, Johnson CH, Yannone SM, Patti GJ, Siuzdak G: Liquid chromatography quadrupole time-of-flight mass spectrometry characterization of metabolites guided by the METLIN database. Nat Protoc 2013, 8:451-460.

16. Graça G, Goodfellow BJ, Barros AS, Diaz S, Duarte IF, Spagou K, Veselkov K, Want EJ, Lindon JC, Carreira IM, Galhano E, Pita C, Gil AM: UPLC-MS metabolic profiling of second trimester amniotic fluid and maternal urine and comparison with NMR spectral profiling for the identification of pregnancy disorder biomarkers. Mol Biosyst 2012, 8:1243-1254.

17. Brace RA, Cheung CY: Regulation of amniotic fluid volume: evolving concepts. Adv Exp Med Biol 2014, 814:49-68.

18. Bahado-Singh RO, Akolekar R, Chelliah A, Mandal R, Dong E, Kruger M, Wishart DS, Nicolaides K: Metabolomic analysis for first-trimester trisomy 18 detection. Am J Obstet Gynecol 2013, 209:65.e1-9.

19. Bahado-Singh RO, Akolekar R, Mandal R, Dong E, Xia J, Kruger M, Wishart DS, Nicolaides K: Metabolomic analysis for first-trimester Down syndrome prediction. Am J Obstet Gynecol 2013, 208:371.e1-8.

20. Diaz SO, Barros AS, Goodfellow BJ, Duarte IF, Galhano E, Pita C, Almeida Mdo C, Carreira IM, Gil AM: Second trimester maternal urine for the diagnosis of trisomy 21 and prediction of poor pregnancy outcomes. J Proteome Res 2013, 12:2946-2957.

21. Zhang A, Sun H, Qiu S, Wang X: Metabolomics insights into pathophysiological mechanisms of nephrology. Int Urol Nephrol 2014, 46:1025-1030.

22. Zheng X, Su M, Pei L, Zhang T, Ma X, Qiu Y, Xia H, Wang F, Zheng X, Gu X, Song X, Li X, Qi X, Chen G, Bao Y, Chen T, Chi Y, Zhao A, Jia W: Metabolic signature of pregnant women with neural tube defects in offspring. J Proteome Res 2011, 10:4845-4854.

23. Coen M, Wevers RA, Lindon JC, Blom HJ: High-resolution 1H NMR spectroscopic investigation of a chick embryo model of neural tube development. MagnResonChem 2009, 47(Suppl 1):S62-67. 
24. Hansler A, Chen Q, Gray JD, Ross ME, Finnell RH, Gross SS: Untargeted metabolite profiling of murine embryos to reveal metabolic perturbations associated with neural tube closure defects. Birth Defects Res A Clin Mol Teratol 2014, 100:623-632.

25. Sanz-Cortés M, Carbajo RJ, Crispi F, Figueras F, Pineda-Lucena A, Gratacós E: Metabolomic profile of umbilical cord blood plasma from early and late intrauterine growth restricted (IUGR) neonates with and without signs of brain vasodilation. PLoS One 2013, 8:e80121.

26. van Vliet E, Eixarch E, Illa M, Arbat-Plana A, González-Tendero A, Hogberg HT, Zhao L, Hartung T, Gratacos E: Metabolomics reveals metabolic alterations by intrauterine growth restriction in the fetal rabbit brain. PLoS One 2013, 8:e64545.

27. O'Connor C, Stuart B, Fitzpatrick C, Turner MJ, Kennelly MM: A review of contemporary modalities for identifying abnormal fetal growth. J Obstet Gynaecol 2013, 33:239-245.

28. Dessì A, Ottonello G, Fanos V: Physiopathology of intrauterine growth retardation: from classic data to metabolomics. J Matern Fetal Neonatal Med 2012, 25:13-8. 23025763.

29. Mimmi MC, Ballico M, Nakib G, Calcaterra V, Peiró JL, Marotta M, Pelizzo P: Altered metabolic profile in congenital lung lesions revealed by $1 \mathrm{H}$ nuclear magnetic resonance spectroscopy. ISRN Analytical Chemistry 2014, 2014:ID 391836. http://dx.doi.org/10.1155/2014/391836.

30. Wu BT, Dyer RA, King DJ, Richardson KJ, Innis SM: Early second trimester maternal plasma choline and betaine are related to measures of early cognitive development in term infants. PLoS One 2012, 7:e43448.

31. Sullivan KM, Hawgood S, Flake AW, Harrison MR, Adzick NS: Amniotic fluid phospholipid analysis in the fetus with congenital diaphragmatic hernia. J Pediatr Surg 1994, 29:1020-1023.

32. Davey M: Surfactant levels in congenital diaphragmatic hernia. PLoS Med 2007, 31:4:e243.

33. Ruano R, Peiro JL, da Silva MM, Campos JA, Carreras E, Tannuri U, Zugaib M: Early fetoscopic tracheal occlusion for extremely severe pulmonary hypoplasia in isolated congenital diaphragmatic hernia: preliminary results. Ultrasound Obstet Gynecol 2013, 42:70-76.

34. Sanz-López E, Maderuelo E, Peláez D, Chimenti P, Lorente R, Muñoz MA Sánchez-Luna M: Changes in the expression of vascular endothelial growth factor after fetal tracheal occlusion in an experimental model of congenital diaphragmatic hernia. Crit Care Res Pract 2013, 2013:958078.

35. Cogo PE, Zimmermann LJ, Verlato G, Midrio P, Gucciardi A, Ori C, Carnielli VP: A dual stable isotope tracer method for the measurement of surfactant disaturated-phosphatidylcholine net synthesis in infants with congenital diaphragmatic hernia. Pediatr Res 2004, 56:184-190.

36. Luks FI, Wild YK, Piasecki GJ, De Paepe ME: Short-term tracheal occlusion corrects pulmonary vascular anomalies in the fetal lamb with diaphragmatic hernia. Surgery 2000, 128:266-272.

doi:10.1186/2049-6958-9-54

Cite this article as: Pelizzo et al: Metabolomic profile of amniotic fluid to evaluate lung maturity: the diaphragmatic hernia lamb model. Multidisciplinary Respiratory Medicine 2014 9:54.

\section{Submit your next manuscript to BioMed Central and take full advantage of:}

- Convenient online submission

- Thorough peer review

- No space constraints or color figure charges

- Immediate publication on acceptance

- Inclusion in PubMed, CAS, Scopus and Google Scholar

- Research which is freely available for redistribution
C Biomed Central 